upper limbs for many weeks results in changes in both the peripheral musculature and the central nervous system. It is well known that common complaints after upper limb fractures include weakness, pain, and stiffness; therefore, pain management is important in the early stages of the rehabilitation of upper limb fractures.

Objectives: This pilot study aimed to investigate the efficacy of graded motor imaginary (GMI) on pain, range of motion (ROM), and function in patients with posttraumatic stiff elbow.

Methods: Fourteen patients with posttraumatic stiff elbow (6 women, mean age: $45.42 \pm 11.26$ years, mean body mass index: $24.29 \pm 3.38 \mathrm{kglm}^{2}$ and mean duration of immobilization: $4.75 \pm 1.03$ weeks) were randomly allocated to either GMI or control groups. The GMI group received GMI treatment in addition to a structured exercise program, and the control group received a structured exercise program (two days per week for six weeks) (Figure 1). The assessments included pain at rest and during activity using the visual analog scale (VAS), elbow active ROM with a digital goniometer (Baseline Evaluation Instrument, Fabrication Enterprises, Inc., White Plains, NY), and upper extremity functional status using the Disability of the Arm, Shoulder and Hand Questionnaire (DASH). The assessments were performed at baseline and after the 6-week intervention.

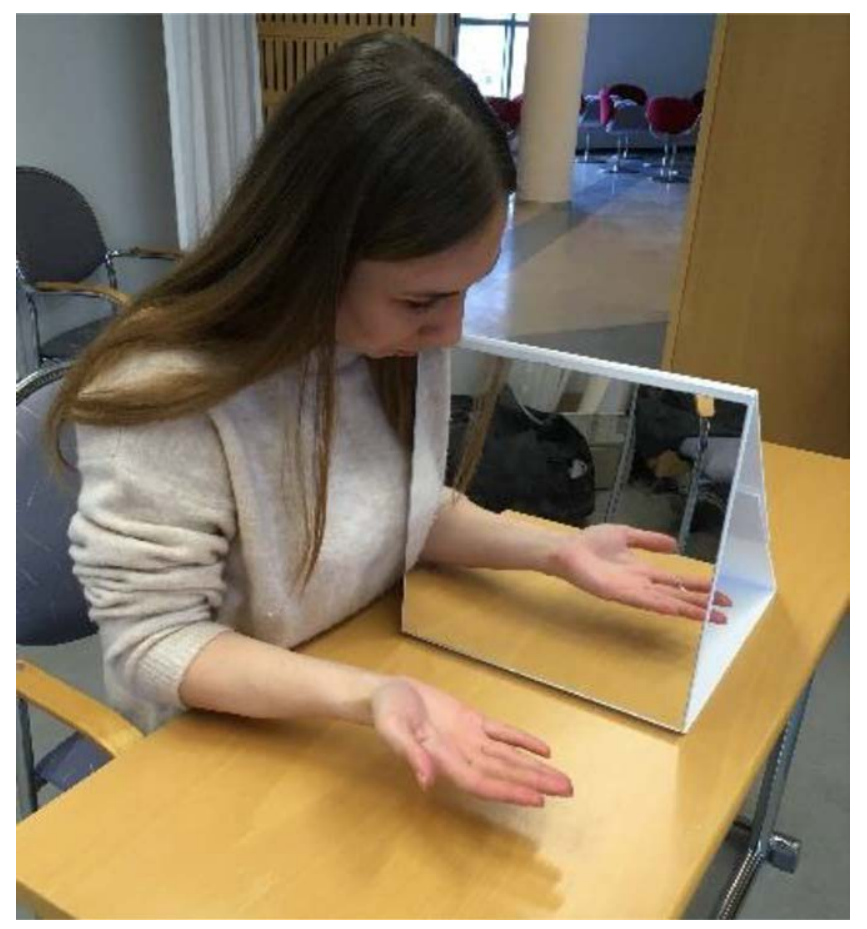

Figure 1. Graded motor imagery performed with mirror box

Results: After the 6-week intervention, there was a significant increase in elbow flexion-extension ROM and supination-pronation ROM, and improvement in DASH score in both groups $(p<0.05)$. However, improvement in VAS-rest and VAS-activity was significantly higher in the GMI group than the control group $(p=0.03$ and $p=0.01$, respectively).

Conclusion: A conservative treatment program consisting of GMI treatment in addition to a structured exercise program applied twice a week for 6 weeks, has been found more effective in decreasing pain in the posttraumatic stiff elbow. It could be concluded that GMI is an effective treatment method for elbow fracture in patients with predominant elbow pain.

References:

[1] Harris JE, Hebert A. Utilization of motor imagery in upper limb rehabilitation: a systematic scoping review. Clin Rehab. 2015:29(11):1092-1107.

[2] Opie GM, Evans A, Ridding MC, Semmler JG. Short-term immobilization influences use-dependent cortical plasticity and fine motor performance. Neuroscience. 2016:330:247-256.

[3] Birinci T, Razak Ozdincler A, Altun S, Kural C. A structured exercise programme combined with proprioceptive neuromuscular facilitation stretching or static stretching in posttraumatic stiffness of the elbow: a randomized controlled trial. Clin Rehab. 2019:33(2):241-252.

Acknowledgments: The present work was supported by the Scientific Research Projects Coordination Unit of Istanbul University-Cerrahpasa (Project No: TDK-2019-33997).

Disclosure of Interests: None declared

DOI: 10.1136/annrheumdis-2020-eular.2660

\section{FRI0618-HPR EFFECTS OF MUSIC THERAPY ON PAIN, ANXIETY, AND VITAL SIGNS IN CHRONIC INFLAMMATORY RHEUMATIC DISEASES PATIENTS DURING BIOLOGICAL DRUGS INFUSION}

S. Boussaid ${ }^{1}$, M. Ben Majdouba ${ }^{1}$, S. Jriri ${ }^{1}$, M. Abbes ${ }^{1}$, S. Jammali ${ }^{1}$, H. Ajlani ${ }^{1}$, H. Sahli ${ }^{1}$, I. Cheour ${ }^{1}$, S. Rekik', M. Elleuch'. ${ }^{1}$ La Rabta, Tunis, Tunisia

Background: Music therapy is based on ancient cross-cultural beliefs that music can have a "healing" effect on mind and body. Research determined that listening to music can increase comfort and relaxation, relieve pain, lower distress, reduce anxiety, improve positive emotions and mood, and decrease psychological symptoms. Music therapy has been used greatly in various medical procedures to reduce associated anxiety and pain. Patients have a high level of anxiety when they are in the hospital, this is the case of patients with rheumatic diseases who consult regularly to have intravenous infusion of biological therapies.

Objectives: The purpose of this study was to examine the effectiveness of music therapy on pain, anxiety, and vital signs among patients with chronic inflammatory rheumatic diseases during intravenous infusion of biological drugs.

Methods: Fifty patients were divided into two groups: The experimental group G1 $(n=25)$ received drug infusion while lestening to soft music (30 minutes); and the control group $\mathrm{G} 2$ ( $\mathrm{n}=25)$ received only drug infusion. Measures include pain, anxiety, vital signs (blood pressure, heart rate and respiratory rate). The pain was measured using visual analogic scale (VAS). The state-trait anxiety inventory (STAI) was used for measuring anxiety, low anxiety ranges from 20 to 39 , the moderate anxiety ranges from 40 to 59 , and high anxiety ranges from 60 to 80 . Vital signs (systolic blood pressure [SBP], diastolic blood pressure [DBP], heart rate [HR], and respiratory rate $[R R]$ ) were measured before, during and immediately after the infusion. Statistical package for social sciences (SPSS) was used for analysis.

Results: The mean age in $\mathrm{G} 1$ was 44.45 years (26-72) with a sex ratio (M/F) of 0.8 . Including the 25 patients, 12 had rheumatoid arthritis, 10 had ankylosing spondylitis and 3 had psoriatic arthritis. The mean disease duration was 8 years. In $\mathrm{G} 2$, the mean age was 46 years (25-70) with a sex ratio (M/F) of $0.75,12$ had rheumatoid arthritis, 11 had ankylosing spondylitis and 2 had psoriatic arthritis. The mean disease duration was 7.5 years. The biological drugs used were: Infliximab in 30 cases, Tocilizumab in 12 cases and Rituximab in 8 cases.

Before the infusion, the patients of experimental group had a mean VAS of $5 / 10 \pm 3$, a mean STAI of $50.62 \pm 6.01$, a mean SBP of $13.6 \mathrm{cmHg} \pm 1.4$, a mean DBP of 8.6 $\mathrm{cmHg} \pm 1$, a mean $\mathrm{HR}$ of $85 \pm 10$ and a mean $\mathrm{RR}$ of $18 \pm 3$. While in control group the mean VAS was $5.5 \pm 2$, the mean STAI was $50.89 \pm 5.5$, the mean SBP was $13.4 \pm 1.2$, the mean DBP was $8.8 \pm 1.1$, the mean $\mathrm{HR}$ was $82 \pm 8$ and the mean RR was $19 \pm 2$. During the infusion and after music intervention in $\mathrm{G} 1$, the mean STAI became $38.35 \pm 5$ in $G 1$ versus $46.7 \pm 5.2$ in $G 2$ ( $p$ value $=0.022$ ), the mean SBP became $12.1 \pm 0.5$ in $\mathrm{G} 1$ versus $13 \pm 1$ in $\mathrm{G} 2(\mathrm{p}=0.035)$, the mean DBP became $8.1 \pm 0.8$ in $\mathrm{G} 1$ versus $8.4 \pm 0.9$ in $\mathrm{G} 2(p=0.4)$, the mean $H R$ became $76 \pm 9$ in $\mathrm{G} 1$ versus $78 \pm 7$ in $\mathrm{G} 2$ $(p=0.04)$ and the mean RR became $17.3 \pm 2.1$ in $\mathrm{G} 1$ versus $18.2 \pm 1.7$ in $\mathrm{G} 2(p=0.39)$ This study found a statistically significant decrease in anxiety, systolic blood pressure and heart rate in patients receiving music interventions during biological therapies infusion, but no significant difference were identified in diastolic blood pressure and respiratory rate.

Conclusion: The findings provide further evidence to support the use of music therapy to reduce anxiety, and lower systolic blood pressure and heart rate in patients with rheumatic disease during biological therapies infusion.

References:

[1] Lin, C., Hwang, S., Jiang, P., \& Hsiung, N. (2019). Effect of Music Therapy on Pain After Orthopedic Surgery -A Systematic review and Meta-Analysis. Pain Practice.

Disclosure of Interests: None declared

DOI: 10.1136/annrheumdis-2020-eular.6027

\section{FRI0619-HPR INVESTIGATION OF THE RELATIONSHIP BETWEEN BIOPSYCHOSOCIAL STATUS AND QUALITY OF LIFE, EMOTION - STATUS AND FUNCTIONALITY IN INDIVIDUALS WITH PSORIATIC ARTHRITIS.}

S. Bulut ${ }^{1}$, E. Ünal ${ }^{1}$, A. Özçadırcı ${ }^{1}$, U. Kalyoncu ${ }^{1} .{ }^{1}$ Hacettepe University, Ankara, Turkey

Background: Due to the chronic processes of rheumatological diseases, patients biopsychosocial effects are revealed.

Objectives: The aim of this study is to evaluate the biopsychosocial status of individuals diagnosed with psoriatic arthritis; to examine the relationship between quality of life, emotion - status and functionality.

Methods: 105 individuals were included in the study. To evaluate the biopsychosocial situation, BETY-BQ (Bilişsel Egzersiz Terapi Yaklaşımı - Biopsychosocial Questionnaire)(1); Psoriatic Arthritis Quality of Life (PsAQoL) Scale to assess quality of life; For the emotion-status assessment; Hospital Anxiety and Depression Scale (HADS-A, HADS-D); Health Assessment Questionnaire (HAQ) was used for functionality. Pearson Correlation Analysis was used in statistical analysis. Results: Descriptive data of the individuals participating in the study were recorded (Table 1).While BETY-BQ was highly correlated with PSAQoL Scale $(r=0.826$, 